\title{
Where Am I? The Literature On Women And Household Poverty Using Systematic Literature Review
}

\author{
Nor Amalina Nazri' ${ }^{1}$, Azizan Zainuddin², Suhaimi Abd Samad ${ }^{3}$ \\ \{noramalinanazri@gmail.com¹, azizan_zainuddin@uitm.edu.my², suhaimi@uitm.edu.my ${ }^{3}$ \} \\ Universiti Teknologi MARA, Malaysia
}

\begin{abstract}
This article compiling the previous studies that have been conducted by the leading scholars on the issue based on the perspective of women poverty to overcome poverty issue. A systematic literature review has been adopted in this article to find the gap of the study. The results shows there are few themes that have been developed based on the literature mainly the labour force participation rate, diversification and intensification issue on women's household and female headed household. Besides this article also highlighted a review on poverty discourse. Therefore, the main aim of this article is to identify the gap from the literature review of the poor women household in Malaysia. Based on the systematic literature review, it shows that there are 15 articles that can be included in this qualitative synthesis. This literature review strive not only to educate but advocate of different avenues regarding women household poverty.
\end{abstract}

Keywords: Poverty alleviation, women prevalence; female headed household; poor women household

\section{Introduction}

Sustainable Development Goals Fund (2019) mentioned that as a way to accelerates sustainable development empowering women and promoting gender equality is crucial. Ending all forms of discrimination against women and girls is not only a basic human right, but it also has a multiplier influence across all other development areas. However, in reality this situation hardly been translated. One of the greatest challenges facing humanity is eradicating poverty although the number of people living in poverty has dropped more than half from 1990 to 2015 which is the rate has dropped from 1.9 billion to 836 million but still there are many people are still struggling to meet their basic human need [1].

According to World Bank (2015), the rate of poverty in the world is about 700 million which is compressed 12 percent of global population as this poverty issue is the major issue in the world. The aim of united nation development is to end poverty by 2030 . In the face of this success, there are many population that unable to access education, health care and thousands of children die before their fifth birth. Because of this poverty issue, there are about 58 million children who out of school in poorest countries.

World Bank (2018) stated that the issue of poverty overwhelming since there are 79 per cent number of people that experiencing poverty specifically in rural area. Chant (2011) mentioned that 70 per cent of world's poor dominate by women population. Women are represented among elderly poor due to the fact that they tend to live longer compared to men. Thus, conjunction to this issue, they tend to have higher poverty rates compared to men [2]. A 
few campaign been established that focus on women that lies in rural areas and need to bears family responsibilities on their shoulders while many women empowerment campaign been conducted that focused on offering education and job opportunities [3]. Women's poverty being the centre of discussion among political around the world. Regarding the complex relationship between gender and poverty, many plans area geared towards addressing underprivileged background failed to take into account [4]

When mentioned about women and poverty it is very much relate to the status of women in various sectors. The poverty level that been faced by the women in the world will lead to unprotected right for them. Obviously, they will face the challenges to cope with that situation. In fact, the Beijing Declaration and Platform for Action, adopted by 189 Member States in 1995, has made a clear declaration that their agenda on women poverty very much focus on the 12 critical areas of concern which inclusive education, employment, health, and so on. With these action plan it will help to build women with a better life. However, specific measures in order to reduce their poverty level are crucial.

In Malaysia context, the Government had been focusing on eradication of poverty regardless of race and ethnicity. As mention in $11^{\text {th }}$ Malaysian Plan (2016), Malaysia has successfully reduced the rate of poverty from $49.3 \%$ in 1970 to $1.6 \%$ in 2014 and the current rate of poverty in 2019 is $0.4 \%$. There is significant gap between the rural and urban dwellers, develop and less develop area in terms of income inequality. Although the mean monthly household income is increasing and progress has been made to reduce the poverty, the proportion of income received in develop area is higher than less develop area. The issue of poverty not only trap the community that live in rural area as a whole but the issue of poverty among women also is a vital issue these day. Therefore, this article tries to find a gap based on scholar views on women and poverty to further develop related knowledge and to provide some recommendations in minimizing the poverty level among women.

Eradicating poverty is important to be done after Malaysia independence 1957. New Economic Policy had been introduced in 1971 as a way to eradicate poverty. The rate of poverty has dropped from 16.7 to 15.1 percent [5]. This shows that through New Economic Policy, it help the government to reduce the rate of poverty in Malaysia as a whole. In line with this issue also government had introduced Government Transformation Program whereby the purpose of this program is to increase quality of life among low middle income people. There are many program had been conducted to reduce the rate of poverty such as through Amanah Ikhtiar Malaysia (AIM). Through this program the society will be provided fund, training and skill as a way to find their own income to support their life. Through this program, society can carry out their own business.

\section{Literature Review}

In this section the method used to retrieve articles related to the causes of women poverty being discussed. The reviewers used the method called PRISMA. The Preferred Reporting Items for Systematic Review and Meta-Analysis (PRISMA) protocol has been used as a guidance for the systematics literature review. The search has been conducted in two major electronic database which are Scopus and Dimensions. These database has been used to locate articles written in English. The search string included the key terms such as women poverty, women poor, female poverty and other as demonstrated in the Table 1. 
Through this systematic literature review had undergone there steps which are identification, screening and eligibility. Through the identification process keywords used in the search process. Relying on the previous study and some words that might have the same meaning were used to find the article through identification process. At this stage, careful screening and duplicated article has been removed [6].

The next stage of systematic literature review is screening process, through screening process out of 527 articles eligible to be reviewed, a total of 165 article articles has been removed. Then the third stage is eligibility. Through the process of eligibility, after careful examination, a total 188 articles were excluded as some of the articles did not focus on women the women poverty itself. Instead of that a total of 174 articles being removed due to the duplication of articles. The last stage of review resulted there are 15 articles that were used for the qualitative analysis [6].

Table 1: Search String

\begin{tabular}{ll}
\hline DATABASE & \multicolumn{1}{c}{ SEARCH STRING } \\
\hline SCOPUS & TITLE-ABS-KEY ( "women poor" ) ) AND ( ( ( "women poor" ) \\
& ) AND ( "poor women" ) ) AND ( "poor household" ) AND ( \\
& LIMIT-TO ( SUBJAREA, "SOCI" ) ), ( "women poor" ) ) AND \\
& ( ( ( "women poor" ) ) AND ( "poor women" ) ) AND ( "women \\
poverty" ) AND ( LIMIT-TO ( SUBJAREA, "SOCI" ) ), ( & "women poor" ) ) AND ( ( ( ( "women poor" ) ) AND ( "poor \\
& women" ) ) AND ( "women poverty" ) ) AND ( "perempuan \\
& miskin" ) AND ( LIMIT-TO ( SUBJAREA, "SOCI" ) ), \\
& ( "female headed household" ), ( "female headed household" ) \\
& ) AND ( "female headed household" ), (female poverty) AND \\
& (female poverty) \\
& ( "female headed household" ) ) AND ( "female headed \\
& household" ), (female poverty) AND (female poverty), AND ( \\
& "women poverty" ), ( "women poor" ) ) AND ( ( ( ( "women \\
& poor" ) ) AND ( "poor women" ) ) AND ( "women poverty" ) ) \\
AND ( "women poor" ) ) AND ( ( ( "women poor" ) ) AND ( & "poor women" ) ) AND ( "poor household" ) \\
\hline
\end{tabular}

Table 1 shows the keywords that had been used in the identification step to retrieve the article. By using keywords in the database system it might help the reviewer to find the article that related to the study. The search string included key terms such as women poverty, women poor and others as demonstrated in the Table 1. The screening of this article is done based on several criteria such as language, timeline and literature type. 


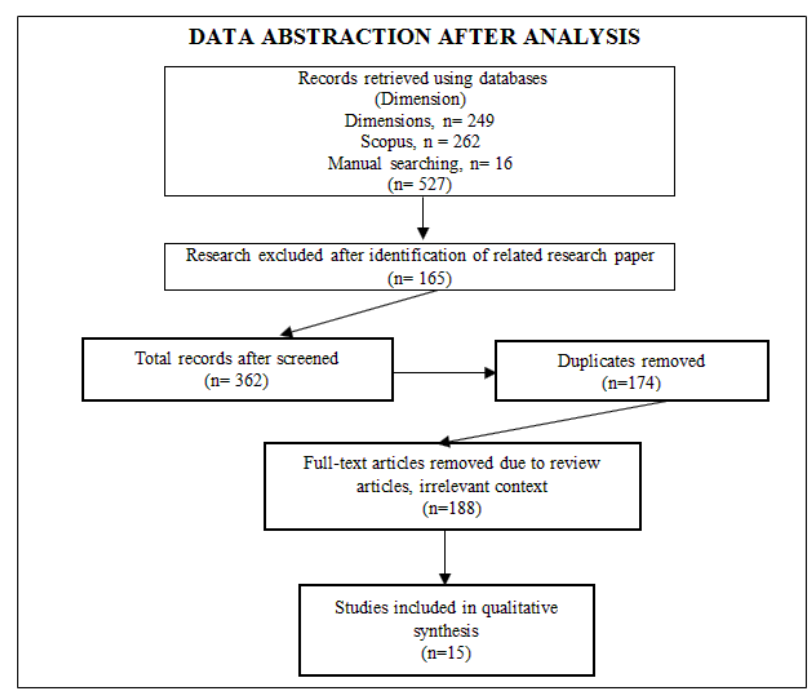

Fig.1. Data Abstraction after Analysis

Figure 1 shows data abstraction after analysis that had been used in Systematic Literature Review. This figure briefly explain the process of PRISMA method that had been used in order to retrieve article from database. The total up of 527 article at first stage had been screened and only 362 article left after 165 article been excluded. After 174 of duplicated article been removed at the end of the step show only 15 article included in this qualitative synthesis.

\section{Result and Discussion}

The result of the research yielded at 527 records. 362 studies were screened at the first place to fulfil the eligibility criteria. After all, the process of data abstraction, screening and filtering there are only 15 articles selected for the final review and further analysis. Based on the review, it shows that there are three causes that lead to women poverty which are female headed household, labour force participation rate and diversification and intensification of women's inputs to household survival.

\section{Causes of Poor Women Household}

a. Female Headed Household

The number of female headed household keep increasing all over the world. For example, the number of female headed household in Latin America keep increasing since forty years in that region [7]. According to Chant (2003), the growing number of female headed household is a good sign as female leadership has its own strength and positive. Happen to be, many report and past studies shows that the increasing number of female headed household closely related to poverty. Women have their own limitation in terms of access to assets and skills training so women cannot get appropriate income [8]

Due to the discrimination against women, gender of the households play an important role because household headed by women are poorer than those headed by men. According to [8], 
women have low literacy rates low wages and have less access to land or equal work. Marital status also affect poverty. Monogamous marriage, divorce and widow are negatively correlated and significant to the probability of becoming poor households. But monogamy marriage has the largest tendency to reduce poverty [9]. In addition, the probability of household also can be affected through household size. The probability of poverty can be reduce when the household have only one household member and vice versa [10]. The probability to poverty will increase with the increasing number of household members. This statement supported by the World Bank by saying that the poor tend to live in larger household members [11]

According to [12] the mean monthly household income for male-headed households is $32.8 \%$ higher than female headed household. Instead of that, female headed household are more vulnerable to poverty compared to men headed household because urban male-headed households earn a median monthly household income $33.1 \%$ higher whereby for rural maleheaded households, the difference was $27.7 \%$ higher, in comparison to their female counterparts [13].

b. Labour Force Participation Rate

Gender gap begins with women's higher barrier to entry compared to men in the labour force. Working-age among women are less likely than men that participate in the labour force in Malaysia by means of different group of women undergoing different level of participation. In recent years, roughly there is equal proportion of working-age population among men and women but LFPR for both gender differ significantly. Malaysian working age population comprises 9.5 million and 9.8 million for women and men respectively during 2017 ( [14]

In conjunction to this issue, $77.7 \%$ of men participated in the labour force whilst only $53.5 \%$ women participated in the labour force. Gender gap in LFPR a long-standing issue in Malaysia since women's LFPR has historically been lower than men's. On the other hand, progress has taken place over the time because within the past two decades, almost $38 \%$ from 38.9 percentage points in 1995 to $24.2 \%$ percentage points in 2017 gender gap in LFPR has narrowed. Based on the progress in a long time period shows that upward trend for women participation rates and corresponding downward trend for men [15]

In the past seven years, the improvement and the narrowing of the gender gap was impressive. From 2010 until 2017, women's LFPR increased by 8.0 percentage points from $45.5 \%$ to $53.5 \%$ which is the increasing shows nine times more than 0.9 percentage points recorded from 1995 until 2010 but men's LFPR has remained stable. Conversely, through international comparisons shows that this gap remains relatively large. Malaysia's gender participation gap is second largest among selected country after India [14]

c. Diversification and Intensification of Women's Inputs to Household Survival

In conjunction with the issue of labour force participation rate, there are increasing of numbers of women that working for income and at the same time hold the responsibility for unpaid reproductive tasks for their spouse or male household members. According to recent analysis by UNRISD (2010), women work more hours in total in order and they spend few hours in work which is paid or deemed enough "productive" to be included in the System National Accounts. Into the bargain, as mentioned by Ofreno and Acosta (2003), poorer the household, the longer women work'. This is because in all six countries such as Argentina, Nicaraguna, the Republic of Korea, Tanzania, South Africa and India was found that women spend more than twice as much as time men in unpaid care work and the situation in India was ten times more. From this situation it shows that, the inequality hours between men's and women's is most noticeable among low income groups [11]. 
From the study shows that women have to be multitasking in handling job as they have to take the responsibility as a worker at the workplace as well as they have to play their role as a wife or mother at home. This shows that women have to do double work or working 'overtime' to play her responsibility as a women. As mentioned by INRISD (2010), women work more hours and they have to spend more time to do something that productive to get the appreciation. Although women have to do more works, the rate of poverty among women still high as mentioned by Chant (2014) since the gender that lies among low income group is dominated by women and Malaysian women rated at the second place after India that have large community of poor women household [11].

Female labour is customarily classified as 'unpaid family worker' because they are primarily engaged in subsistence rather than commercially oriented activities. Due to this issue, women's economic contribution are underestimated and they do not have protection at old age. Zumilah (2010) stated that women's economic contribution and participation in development needs to be acknowledge especially for rural poverty eradication [16]Therefore, the gap of study that has been found through the perspective of various scholars who most of them related with the causes of women poverty as female-headed household or single mother, labour force participation rate and diversification and intensification of women's inputs to household survival that hit women as a whole. So this study will ignites the causes that makes the existence women poverty as a whole.

\section{Conclusion}

This article has compiled the prevalence of poverty among women as poverty thought to be foreseeable consequences for women through a previous literature. In order to provide essential information for holistic understanding, placing the underpinning the cause of women poverty where the phenomenon has grown from really allowed for the rest of the review to build up. Most of the scholars highlight the same causes and prevalence that lead to poor women household so it is hope that through this article can help the government or policy maker to reduce the rate of women poverty as a whole specifically for minority group that may get less attention from the government. This review highlight the causes that lead to women poverty in Malaysia. There are many factors that lead to women poverty but the causes that had been highlighted in this article is the main causes that being the issue among women as a whole especially in rural area that get less attention from the government.

There are many ways can be done as a way to minimize women poverty in the community such as the government could identify minority group like single mother or female headed household that have many family members and give them some skill and capital for them to run their own business. By this way they will have their own financial and continuous income compared to the financial aid that had been provided by the government somehow those aid sometimes cannot help these women that stuck under poverty to fulfil their basic needs. For example the programme that had been done by Malaysia government like Amanah Ikhtiar Malaysia whereby through this programme women had been programme some fund and skill for the to start their own business. By this way they will have their own monthly income without hoping on government to fulfil their basic need. Thus, it help to reduce or decrease the number of women that involve or trap under poverty.

Instead of that in order to increase opportunity for women to exercise their right equally, women's equal access to decision making should be promoted. Enabling women to participate 
equally in the organization or governance structure may help to define their development and strategies. By this way it will make critical contribution to addressing underlying poverty issue. Some women did not get their own right to make their own decision as they have to follow their family or spouse decision. Because of this situation it had restricted the right for these women to develop themselves and to provide their own financial income. Thus, women also need to have equal right to make decision as a way to minimize poverty issue from continuously happen.

Last but not least putting an end to poverty issue requires providing opportunities for all individuals especially women to thrive through education. As people know education can change people life. To have equal right of education should be given to every women so that they also can interfere and be decision maker to support themselves in terms of their right. Good education background may help these women out of poverty. It is necessary investment for peaceful and poverty free when women get equal access to a good quality education. Education also may help women to defy social limits based on what they can do or cannot do. For example, good education can help to empower women to choose how many children they may have or how many time they get pregnant. As we concern, the probability of poverty would increase if there are many members in the family. Hence, when women are given exposure through education they may decide good and bad directly this thing may help to minimize the poverty among women as whole.

\section{References}

[1] „Social Development Goals Fund,“ 2019. [Online]. Available: http://socialdevelopmentgoals.

[2] T. D. Thobejane a N. A. Nyati, „Poverty among Female Headed Household in Matabeleland South Province in Zimbabwe: A Perennial Problem or an Enlightening Experience?,“ Gender \& Behaviour, 2018.

[3] R. B. Gaidzanwa, „Women and Land in Zimbabwe,“ 2011.

[4] S. Chant, ,Women in Cities: Prosperity or Poverty? A Need for Multi-dimensional and Multispatial Analysis,“ 2015.

[5] A. F. Wan Nor Azriyati, W. H. Kok a N. R. Hanif, „Pembasmian Kemiskinan Bandar ke arah Bnadar Inklusif dan Sejahtera: Cabaran Kuala Lumpur,“ 2011.

[6] H. A. M. Shaffril, S. E. Krauss a S. F. Samsuddin, „A systematic review on Asian's farmers' adaptation practices towards climate change," Science of the Total Environment, 2018.

[7] Liu, C.et.al, „Female Headed Households and Living Conditions in Latin America,“ p. 2016.

[8] Javed, Zahoor Hussain a A. Asif, , Female Household and Poverty : A Case Study of Faisalabad District. International Journal of Peace and Development Studies,“ 2011.

[9] Anyanwu a C. John , „, Marital Status, Household Size and Poverty in Nigeria:Evidence from 2009/2010 Survey Data,“ 2013.

[10] S. Horrel a K. Pramila, „Poverty And Productivity in Female-Headed households in Zimbabwe,“ The Journal of Development Studies Vol 43, issue 8, 2007.

[11] S. Chant, ,Exploring the "feminisation of poverty" in relation to women's work and home-based enterprise in slums of the Global South. ." International Journal of Gender and Entrepreneurship,, pp. 296-316, 2014

[12] Y. P. Jung, „Poverty in Malaysia“.

[13] „The household income survey (HIS), “ 2016.

[14] Khazanah Research Institute, „,The State of Household 2018 "Different Realities",“ 2018. 
[15] Khazanah Research Institute, „The Malaysian Workforce: A Changing Landscape,“ Khazanah Research Institute, 2018.

[16] Z. Zainalaludin, A. Jamaluddin, S. Abd Shukor a N. Saidi, „Gender and Vulnerable Types among Vul nerable Member in Malaysia Fisheries and Aquaculture Community,“ International Journal for Studies on Children, Women, Elderly and Disabled, 2017. 